\title{
A Cost-Effective IoT Model for a Smart Sewerage Management System Using Sensors
}

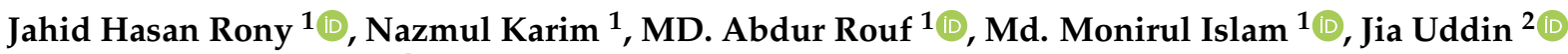 \\ and Momotaz Begum 1,*(D) \\ 1 Department of Computer Science and Engineering, Dhaka University of Engineering \& Technology, \\ Dhaka Gazipur 1707, Bangladesh; 174067@student.duet.ac.bd (J.H.R.); nk.duet@gmail.com (N.K.); \\ abdurrouf.cse.duet@gmail.com (M.A.R.); monir.duet.cse@gmail.com (M.M.I.) \\ 2 Technology Studies Department, Endicott College, Woosong University, Daejeon 300-718, Korea; \\ jia.uddin@wsu.ac.kr \\ * Correspondence: drmomotaz@duet.ac.bd
}

check for updates

Citation: Rony, J.H.; Karim, N.; Rouf, M.A.; Islam, M.M.; Uddin, J.; Begum, M. A Cost-Effective IoT Model for a Smart Sewerage Management System Using Sensors. J 2021, 4, 356-366. https://doi.org/10.3390/j4030027

Academic Editors: Larisa Ivascu and Florin Dragan

Received: 21 May 2021

Accepted: 13 July 2021

Published: 15 July 2021

Publisher's Note: MDPI stays neutra with regard to jurisdictional claims in published maps and institutional affiliations.

Copyright: (c) 2021 by the authors. Licensee MDPI, Basel, Switzerland This article is an open access article distributed under the terms and conditions of the Creative Commons Attribution (CC BY) license (https:// creativecommons.org/licenses/by/ $4.0 /)$

\begin{abstract}
The sewerage system is a primary element of a city and is responsible for the congestion of both rain and gray water from homes and industries. It is essential to have a monitoring system and a plan to perform prior expansion in the sewerage management system, to avoid massive disruption. However, there is no monitoring system in several overpopulated cities in the world, and the expansion process faces myriad difficulties and takes much time. This paper presents a model for an intelligent sewerage management system that provides real-time monitoring without any major changes to the previous system, using water sensors, a Global System for Mobile Communications (GSM) module, and a micro-controller. The condition of the sewerage acts as an input through the sensors; then, the microcontroller stores the value in the cloud and performs waste collection depending on the current situation. Meanwhile, after processing, the information reaches the monitoring system. Various trial installations of the proposed system have shown that it enables real-time monitoring to observe live conditions and helps to prevent sewerage blockage caused by solid waste. Considering a deficient cost model, this system can intensify the performance of poorly managed sewerage systems.
\end{abstract}

Keywords: sewerage monitoring system; internet of things (IoT); real-time monitoring; water level sensors

\section{Introduction}

Human health denotes the mental, social, and physical state of a lifestyle, not only a disease-free condition [1]. To lead a healthy life, it is essential to live in a healthy environment; the ingredients related to a healthy lifestyle in a city depend on several issues, and one of them is the sewerage management system. When it comes to the management of the sewerage system in a heavily populated country such as Bangladesh, it is quite complicated [2]. Dhaka, the capital of Bangladesh, is the sixth most densely populated city in the world [3], having more than 21 million inhabitants [4] with a density of 46,997 people per square kilometer [5]. However, to maintain the sewerage system, engineers face different challenges such as changes in real-time information, surveying, maintaining, and expansion, and with limited resources, they often fail. The failure of the sewerage system can release harmful gases like hydrogen sulfide and methane. As a result, people suffer from various infections and cardiovascular diseases [6].

To avoid such situations, the Dhaka water supply and sewerage authority (DWASA) is always trying to survey and expand in advance [7]. Unfortunately, most of the existing drainage system was planned a long time ago without proper supervision or capability to handle such a significant number of inhabitants. Nevertheless, in many places, the drain lines are congested, and rivers and canals have been forced to disappear because 
of the city's waste dumping [8]. For example, the country's poor drainage management came to light in 1998 and again in 2017, when $68 \%$ and $48 \%$ of the land were flooded [9], respectively, causing an enormous loss to the country's economy.

On the other hand, the waste management system is another vital issue for a healthy city's environment. In that regard, the conditions in Bangladesh are truly miserable [10]. Because of the lack of awareness, people often throw waste onto the roads, which causes insoluble waste like polythene and plastic bottles to enter the sewerage line and block the drainage system. It is quite hard to manually determine the clogged area. Subsequently, maintenance becomes time-consuming, causes economic loss, and people suffer tremendously. In Figure 1, a flow diagram of conventional sewerage maintenance is presented, where complaints from a user or a time-scheduled survey trigger problem identification, which may take a long period of time. The Bangladesh government has taken various steps to boost the system in Dhaka and bring other cities under a similar sewerage network, but those steps were not able to fulfill the targets.

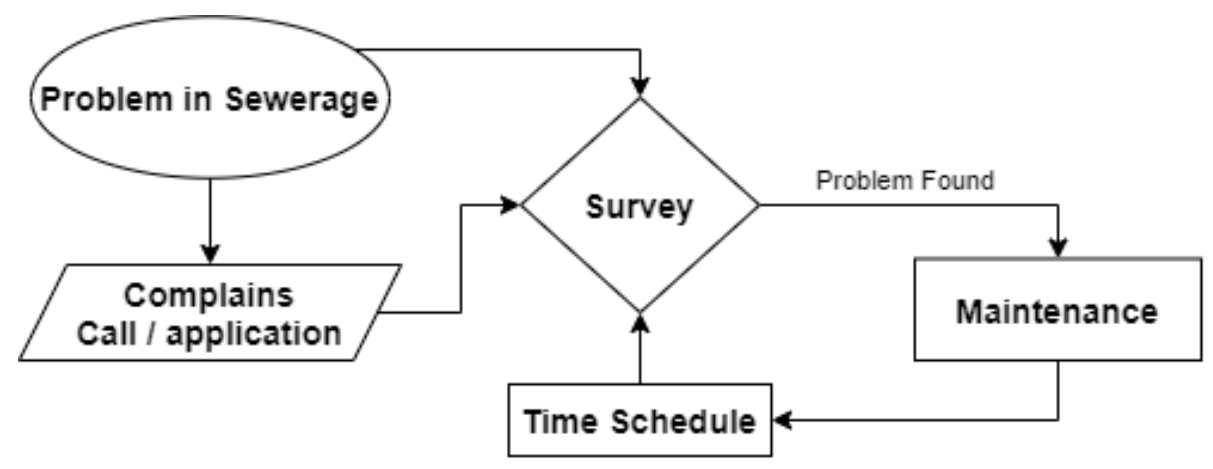

Figure 1. Flow chart of a man-powered sewerage maintenance system.

Today's world is more data-driven and automation-oriented, and the internet of things (IoT) [11] is like a gift to us. Internet-connected objects that can store and exchange data without human interruption over a wireless connection represent an IoT system. Nowadays, cars, refrigerators, lights, and all other types of appliances are connected through the IoT. Briefly, the IoT gives us an opportunity to build and control a system cost-effectively and efficiently.

Several previous studies in sewerage systems proposed implementing a vacuum sewerage system [12], a camera monitoring system [13], or fitting a net in maintenance holes [14], but because of the nature of Dhaka's sewerage system, none of those methods achieved the desired target. With this regard, our motivation is to construct a very costeffective system that can be implemented, without changing the conventional sewerage, to provide real-time monitoring and an automatic waste removal mechanism.

Overall, the problems of a conventional sewerage system in impoverished countries are that they do not have real-time monitoring or a data collection method, an alerting system to act quickly for the worst-case scenario, or a mechanism to separate the solid waste that causes blockages. Moreover, it is time-consuming and expensive to establish and maintain such a system that provides modern facilities.

The following contribution is presented in this paper:

- Low-cost real-time monitoring.

- Overflow detection.

- SMS alerts.

- Waste-removing mechanisms.

This paper presents a smart sewerage management system that addresses the stated problems at an attractive cost. The IoT system allows real-time monitoring to observe the current condition of the drainage system by getting input through sensors. In addition, 
there is a primary waste-removing unit for non-disposable waste that can automatically collect insoluble floating waste, like plastic bottles, to a moving conveyor belt for avoiding blockages. Besides this, an automatic graphical report shows vital information such as water level, overflow information in the area. In addition, an SMS (short message service) giving the affected area's location is sent to the authority immediately, whenever overflow is detected.

The rest of the paper is as follows. Section 2 represents a literature review of previous works, then the methodology of the system is presented in Section 3, and Section 3.1 shows the architectural overview of the system. Hardware configuration and system setup are briefly explained in Sections 3.2 and 3.3 respectively. In Section 4, the result and performance of the system are evaluated from different perspectives. The paper concludes with future plans in Section 5.

\section{Literature Review}

For a modern and healthy life, a sewerage system is essential. As a result, various works have been proposed regarding sewerage monitoring and automation. Saba Latif et al. [15] present a system for transforming a graph model into a formal model using the Vienna development method-specification language (VDM-SL) to predict and control the water flow. The authors of [16] report an approach for a flood prediction system in the United Kingdom by analyzing sensor data for live monitoring with distributed sensors. In addition, a GIS and IoT-based management system [17] was implemented in Hainan province, China, which contains modules like GIS management and an analysis control center, sewerage pipe network grid management, a dynamic pipe network simulation, and information control. Consequently, Sajedul Talukder et al. proposed a system for an automated routine checkup and waste filtering system using Arduino [14].

The authors of [18] report the flow and quality check of dust water in urban areas using a comprehensive mathematical model. A monitoring system based on a wireless mesh network is presented [19] to solve the problems of a conventional monitoring system for the sewerage treatment plant. Sharmad Pasha [20] uses monitoring and sensing for IoT with MatLab analysis using different micro-controllers. Tigor Hamonangan Nasution et al. [21] proposed a prototype of an electric appliance control tool via SMS by using GSM, which does not depend on a mobile device platform. Different approaches to maintaining communication between the IoT and a cloud database have been proposed earlier, such as Li, L. et al. [22], who present a way that Wi-Fi can be utilized in the IoT, then Novo Oscar et al. show the usage of a cellular network [23]; similarly, ZigBee [24] or LoRa [25] can be utilized for communication. In the application of IoT, different papers [26] show how trash and garbage collection or even aquatic fisheries [27] can be modernized by predictive analysis using different machine learning techniques, such as k-means clustering.

However, for a city that is densely populated and has a very poor sewerage management system, like Dhaka City, these aforementioned methods do not work well and present various difficulties. This paper proposes a new, comprehensive IoT-based method to develop a monitoring, survey, and automatic waste removing system, including an alert, within the existing system in a very cost-effective way.

\section{Methodology}

Figure 2 shows the block diagram of the proposed methodology. It has three parts; the system configuration shows how the architecture of the proposed system is arranged in Section 3.1. Then, the system diagram, 3D design and function of different parts are shown in Section 3.2, Hardware Configuration. Then, the prototype and experimental setup are discussed in Section 3.3, System Setup. 


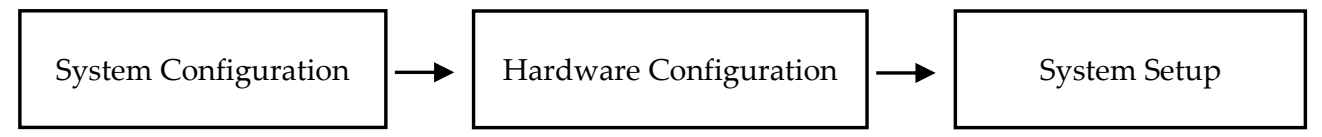

Figure 2. Block diagram of the proposed methodology.

\subsection{System Configuration}

The proposed system works on three basic units: a data collection unit, a processing and communication unit, and a monitoring unit, as shown in Figure 3. The data collection unit collects the raw data from the environment using sensors and sends the data to the processing unit. Afterward, the processing and communication unit processes the raw information into logical data, then establishes network communication to store the data in a cloud database. The communication system supports both GSM and Wi-Fi technology to avoid network disruption. At the last monitoring unit, the system fetches the cloud data and presents a graphical view containing the necessary data for live monitoring.

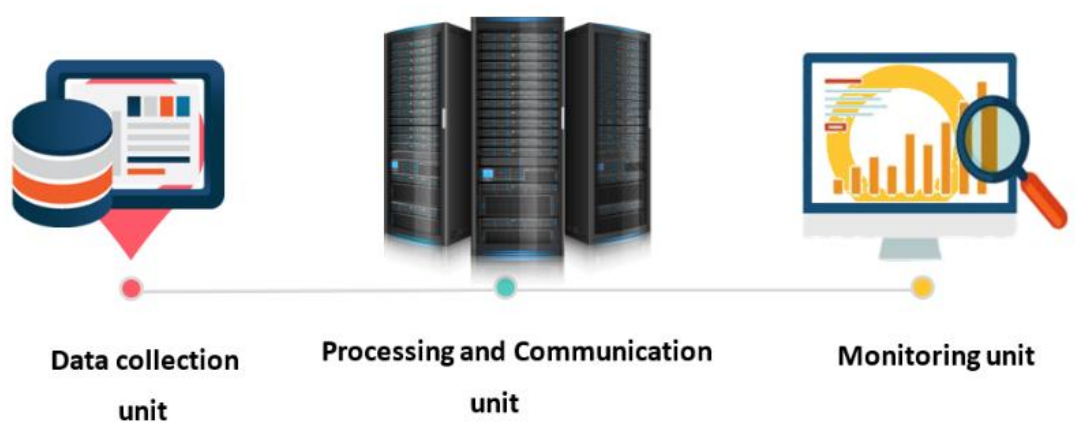

Figure 3. Architectural overview of the proposed system.

\subsection{Hardware Configuration}

The hardware structure of the proposed smart sewerage systems consists of a metal body, sensors, motor section, and controlling unit. Figure 4 shows the hardware configuration of the proposed system. Multiple water sensors are used to detect the level of water and send the signal to the micro-controller. Here,"ESP32" is the main micro-controller, which is a low-cost, power-efficient microcontroller with built-in Wi-Fi and dual-mode Bluetooth [28]. Wi-Fi technology is available everywhere. As a result, Wi-Fi is applied primarily in this study as the data communication medium, and to connect and store data in the cloud database. However, for long-range and large-scale implementation, using LoRa is preferred.

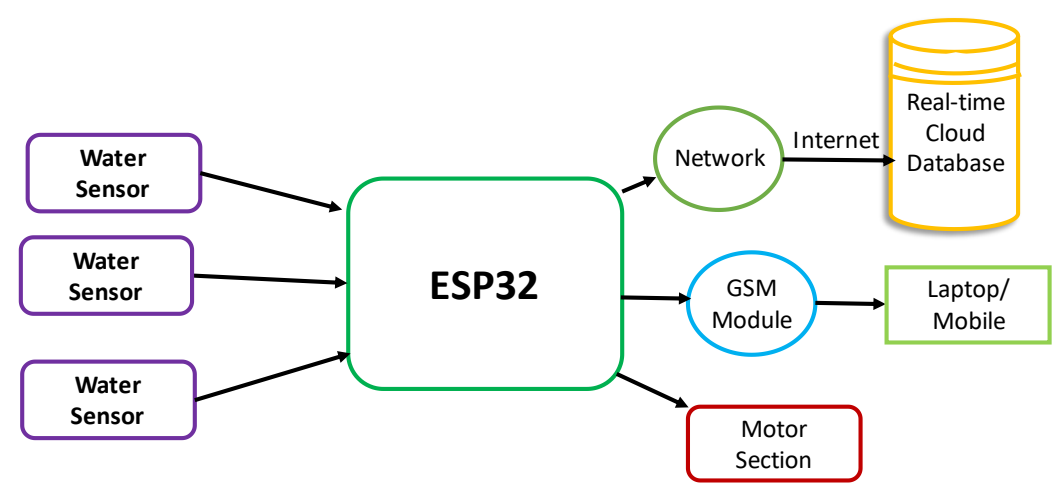

Figure 4. System diagram of the proposed system. 
For SMS notification to the water authority through a mobile phone, a GSM module is utilized. This module uses GSM mobile technology [29] that provides a data link to a remote network. For cloud data storage and analysis, the "ThingSpeak" [30] service is utilized. The motor section consists of two 12V DC motors and two conveyor belts for waste removal. These DC motors move the conveyor belt, which withdraws the floating sewage from the drain and onto the upper conveyor. Figure 5 shows the hardware configuration of the proposed system in 3D design.

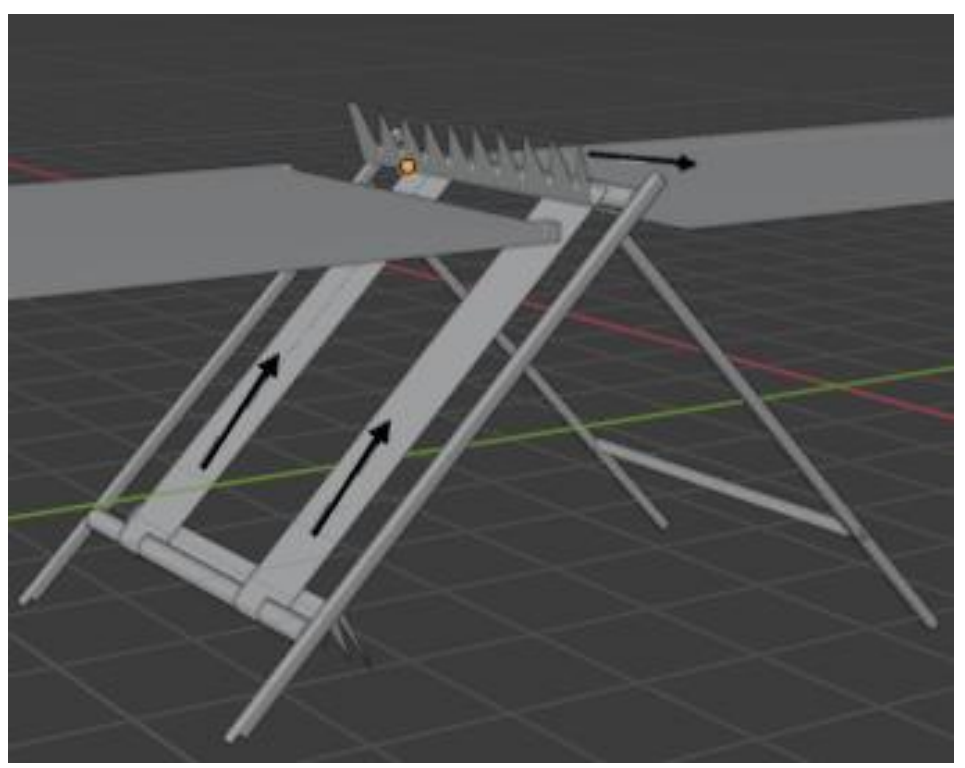

Figure 5. Hardware configuration in 3D design.

\subsection{System Setup}

A custom-designed control unit was designed to put all the electric components in a compact, small space as shown in Figure 6, where (a) shows the front of the circuit board and (b) shows the back. In addition, all the connection is designed to connect through a detachable connector. As a result, the module can be replaced within a short time. The controller is provided with $12 \mathrm{~V} \mathrm{DC}$ input. The motor driver gets direct $12 \mathrm{~V}$ input, and after that, an integrated voltage control IC converts $12 \mathrm{~V}$ to $5 \mathrm{~V}$ for sensor and microcontroller supply. A $12 \mathrm{~V}$ lithium polymer (LIPO) battery with a $25 \mathrm{C}$ discharge rate is used as the primary power and backup source, which is connected to the charging unit. Solar power or a conventional AC source can also be used with an AC-to-DC converter that can convert the supplied AC to $12 \mathrm{~V}$ DC.

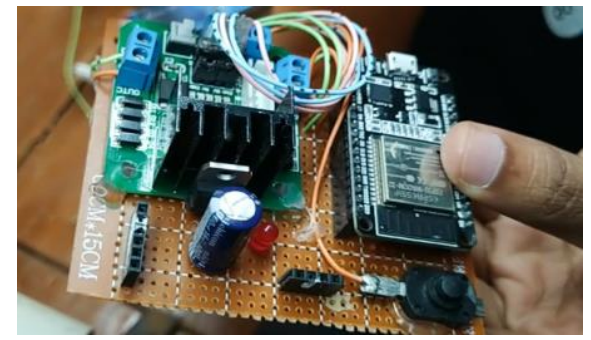

(a)

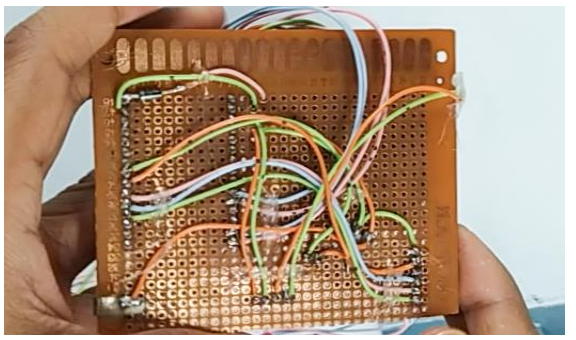

(b)

Figure 6. Our custom-made control unit: (a) front; (b) back.

The prototype of the proposed smart sewerage system was established in a drain inside DUET, Gazipur, Bangladesh, as shown in Figure 7. Under the usual circumstances, 
the overall system worked perfectly without a loss of integrity. The system prototype was connected to the campus $\mathrm{Wi}-\mathrm{Fi}$, and data was monitored via mobile internet connection.

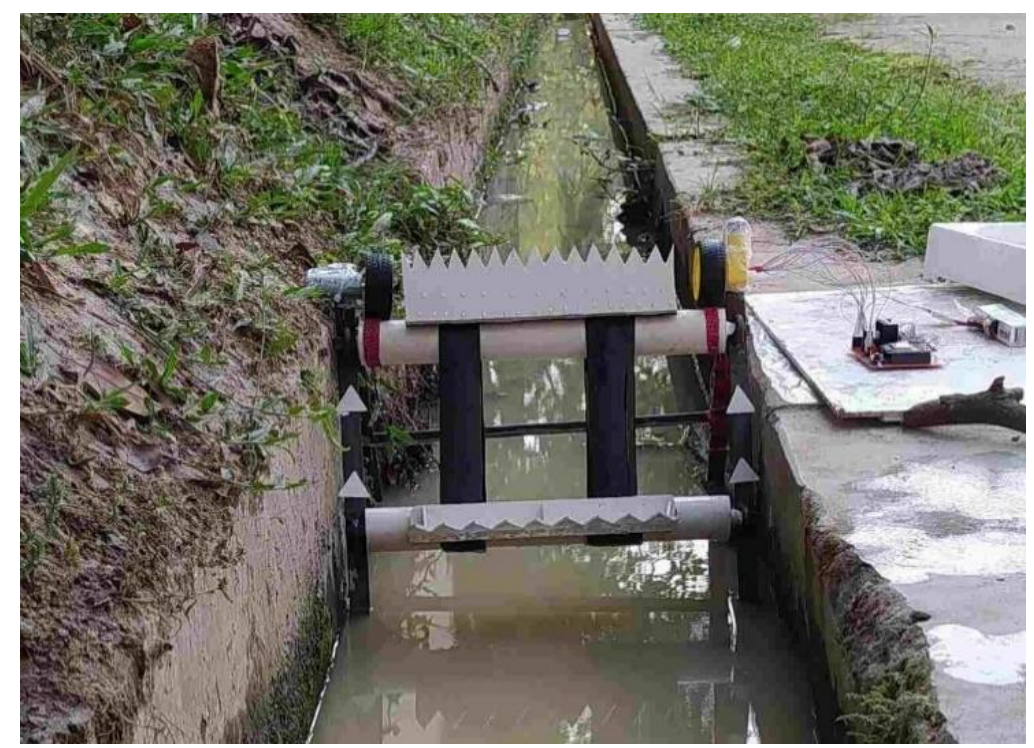

Figure 7. System prototype running in a drain of DUET.

In addition, an artificial flow of water and plastic waste was provided to test the system, and the proposed system worked properly. For the monitoring procedure, the system does not need to input the sensor value every second, so it activates the sensor after a certain period of time, which gives us the advantage of power-saving. A rechargeable LIPO battery, which powers the system, can provide more than a week of power backup for the data collection and processing unit without additional electricity.

\section{Results and Discussion}

After the establishment of the prototype in several places inside the DUET, Gazipur, campus under the usual scenarios, the system had successfully achieved its target. Three data fields of integers ( 32 bits each) to a total of 96 bits, the first containing water level readings from the sensors and the other two containing motor speeds, were carried out in the MATLAB platform for processing. In Table 1, certain data exported from the system are shown. The first column contains the date in YYYY-MM-DD format and time in $24 \mathrm{H}$, HH: MM: SS format. The timestamp is used as taken from the server time. The water level and waste collection unit's motor speed are shown in the second and third columns, respectively, in the range of 0 to 100. Finally, the last column reports the action taken by the system. For example, when the date and time are 2021-04-10, 16:45:21 UTC, the water level is 0 , so the waste collection unit stays idle; that is why the motor speed is at $0 \%$. For 2024-04-10, 16:47:23 UTC, the water flows at a 50\% level, the motors start, and activate the waste collection unit. When the water level is $100 \%$, the waste collection unit works at 100\%, such as for 2027-04-10, 16:48:54 UTC. To adjust the speed of the waste collection unit, an instant water level gain or reduction have a softer impact on motor speed, such that it reduces/increases the speed step by step, not linearly. For 2029-04-10, 16:49:54 UTC, the water level has just decreased; the system waits for the next reading in order to change the motor speed. If the next reading declines, then the motor should decrease in speed, so the speed is reduced in the next step. 
Table 1. Data collected from the cloud database.

\begin{tabular}{|c|c|c|c|}
\hline Date/Time & $\begin{array}{l}\text { Water } \\
\text { Level }\end{array}$ & $\begin{array}{c}\text { Waste Collection } \\
(\%)\end{array}$ & Remark \\
\hline 2021-04-10 16:45:21 UTC & 0 & 0 & No water \\
\hline 2021-04-10 16:45:51 UTC & 25 & 0 & Minor water flow \\
\hline 2022-04-10 16:46:22 UTC & 50 & 25 & Mid-level water \\
\hline 2023-04-10 16:46:52 UTC & 50 & 50 & Mid-level water \\
\hline 2024-04-10 16:47:23 UTC & 50 & 75 & Motor start, mid-level water \\
\hline 2025-04-10 16:47:54 UTC & 50 & 75 & Mid-level water \\
\hline 2026-04-10 16:48:24 UTC & 50 & 75 & Mid-level water \\
\hline 2027-04-10 16:48:54 UTC & 100 & 100 & $\begin{array}{l}\text { Water level increase, motor } \\
\text { speed increase }\end{array}$ \\
\hline 2028-04-10 16:49:24 UTC & 100 & 100 & Full level water \\
\hline 2029-04-10 16:49:54 UTC & 50 & 100 & $\begin{array}{l}\text { Water level decreased high } \\
\text { to mid }\end{array}$ \\
\hline 2030-04-10 16:50:24 UTC & 50 & 75 & Mid-level water \\
\hline 2031-04-10 16:50:55 UTC & 50 & 50 & $\begin{array}{l}\text { Mid-level water, motor } \\
\text { speed decrease }\end{array}$ \\
\hline 2032-04-10 16:51:25 UTC & 25 & 25 & low level water, motor stop \\
\hline 2033-04-10 16:51:55 UTC & 25 & 0 & Minor water flow \\
\hline
\end{tabular}

The visual presentation of certain data shown in Figure 8 represents how the motors' speed behaves with respect to the water level. Here, the X-axis represents time in HH:MM:SS format and the Y-axis shows the water level, in a range from 0 to 100. After passing the maximum water level at 100, water overflow is detected and an SMS notification is sent, as shown in Figure 9, containing the location of the affected area and the sensor serial number when the overflow is detected.

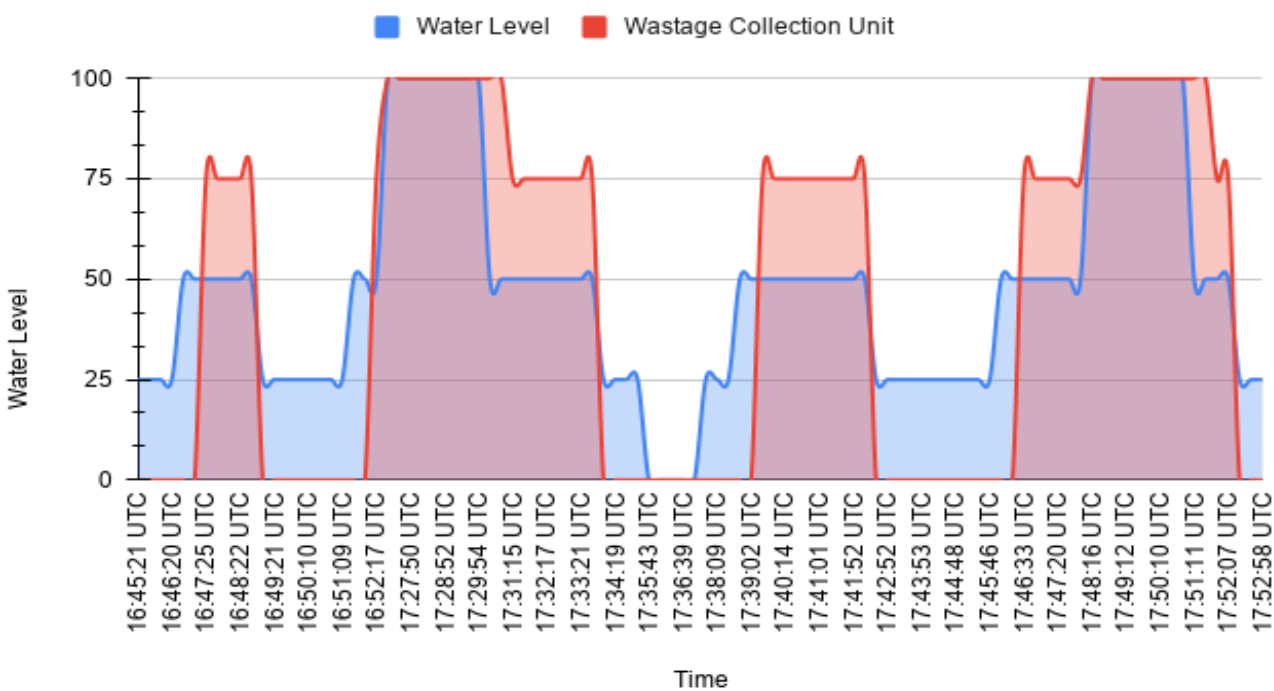

Figure 8. Visual presentation of the relationship between water level and the conveyor belt's motor speed. 


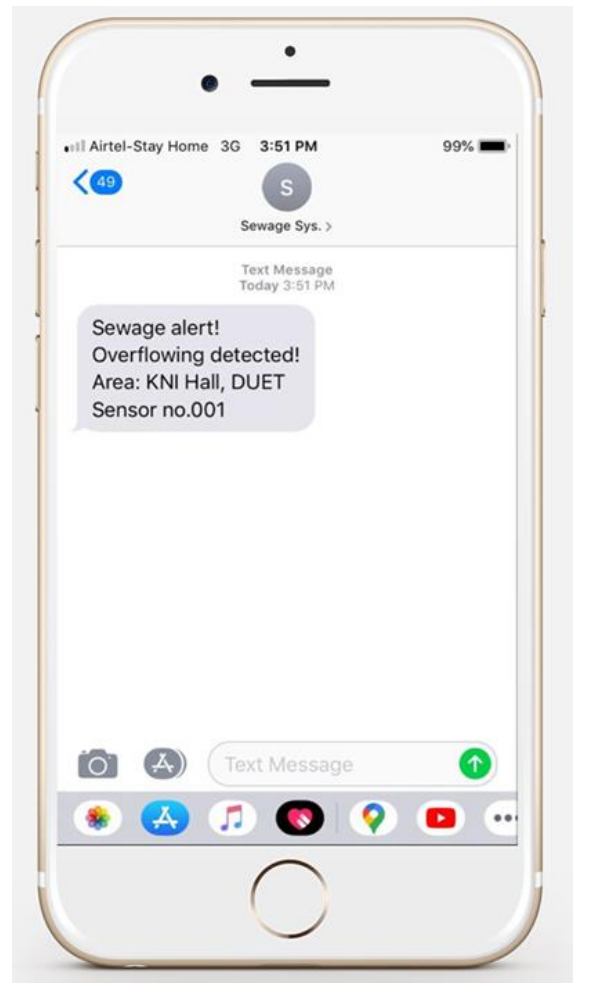

Figure 9. SMS notification when there is an overflow in the system.

The live monitoring can be performed through the web app in both mobile and desktop environments, from anywhere with internet connectivity, which is another advantage of this system. Figure 10 demonstrates the monitoring, shown in web-view on a mobile phone.

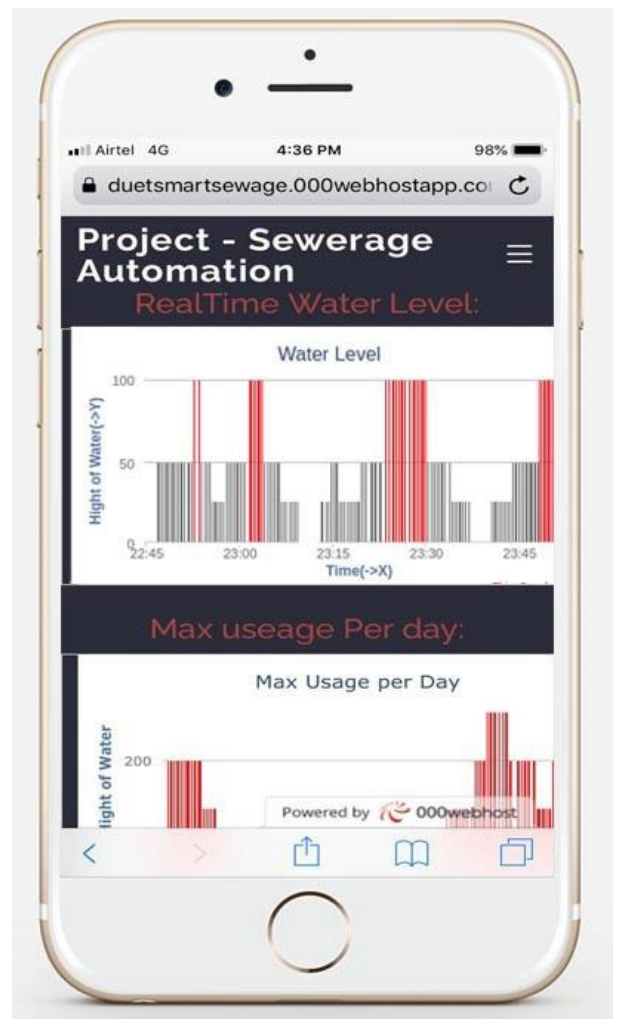

Figure 10. Monitoring through a web app on a mobile phone. 
The detailed cost information of the proposed model is presented in Tables 2 and 3. An "ESP32" microcontroller, which has a market value of around 400 BDT, one motor driver worth 300 BDT, two DC motors worth 500 BDT, as well as three water sensors worth $300 \mathrm{BDT}$, are used. In addition, the system requires a LoRa Ra-02 transceiver and other cheap electronic components, along with a metal body costing around 500 BDT, which includes 7805IC for voltage conversion, capacitor, LED, veroboard and cables, a metal frame, bearings, and a belt for the hardware body. The hardware implementation cost of the proposed smart sewerage system is approximately 2400 BDT (equivalent to USD 28), and the maintenance cost is meager.

Table 2. Cost estimation for one set of hardware.

\begin{tabular}{ccccc}
\hline S1. & Equipment & Unit & Price (BDT) & Cost (BDT) \\
\hline 1 & ESP32 & 1 & 400 & 400 \\
\hline 2 & LoRa Ra-02 & 1 & 400 & 400 \\
\hline 3 & Motor Driver & 1 & 300 & 300 \\
\hline 4 & 12V DC Motor & 2 & 250 & 500 \\
\hline 5 & Water Sensor & 3 & 100 & 300 \\
\hline 6 & Others & 500 & 500 \\
\hline \multicolumn{2}{r}{ Total $=$} \\
\hline
\end{tabular}

Table 3. Cost estimation of 30 units.

\begin{tabular}{llll}
\hline & & Cost for 1 Unit (BDT) & Cost for 30 Units (BDT) \\
\hline Device & Cost shown in Table 2 & 2400 & $2400 * 30=72,000$ \\
\hline Connectivity & Internet access & 500 (per month) & $500 * 2=1000$ \\
\hline Application & ThingSpeak & $\begin{array}{l}4750 \text { (per month, up to } \\
250 \text { channel) }\end{array}$ & 4750 \\
\hline Service & Standard web hosting & 500 (per month) & - \\
\hline Others & $\begin{array}{l}\text { Expected hardware } \\
\text { maintenance and } \\
\text { energy consumption }\end{array}$ & 300 (per month) & 9000 \\
\hline Total & & $=8450$ & $=87,250$ \\
\hline
\end{tabular}

For a mega-city like Dhaka, 15 to 30 devices need to be installed per square kilometer of sewer, depending on the current condition of the sewerage system and the area's population. Therefore, the cost of the initial installation of 30 units of the system would be around 87,250 BDT, as shown in Table 3. The expected hardware maintenance cost is estimated as $10 \%$ per device, then, including the power consumption cost and all other costs, the total is estimated to be 300 BDT per unit. The cloud database service "ThingSpeak" charges around BDT 4750 for from 0 to 250 channels, which is why the unit cost seems high, but in large-scale implementation, this will be drastically reduced.

Here, for connectivity, we have designed 2 internet-enabled gateways that will work as an internet connection point for all 30 nodes, and among all the nodes, data can be shared through a mesh network built with LoRa. This system is in contrast to the present system that is now used in the city, which needs more manpower and costs around 30,000 BDT every month, solely for the maintenance of every square kilometer area [14,31]. All the parts of the proposed system are modular, and those modules are connected through removable connectors, so that the defective parts can be changed without any difficulty. As a result, maintenance is less time-consuming, technically simple, and economically 
inexpensive. Besides, the scalability of the system is high, due to the easy implementation process and cost-effectiveness. Thus, the proposed system can tremendously improve the state-of-the-art manual system in various ways.

\section{Conclusions}

This paper proposed an IoT-based system that provides real-time monitoring and alert systems, with a waste removing mechanism that works without any major modifications within the conventional system, such as implementing a full new route or the acquisition of land for expansion. From the prototype establishment in DUET, Gazipur campus, the new system was found to be more efficient, convenient, and modern than the old system. Because of the monitoring and alarm functionality, the water authority is able to respond quickly to any unusual occurrence and make data-driven decisions. Then, the live conditions activate the waste collection feature, which prevents unnecessary energy loss. In addition, the related personnel can monitor the whole system with just an internet-connected device from anywhere in the world, which gives great portability. However, because of money, time, and resource constraints, a prototype of the actual system was implemented, although the preliminary trial did work well and outperformed the conventional method from every perspective. Further development, like a more powerful motor, power backup, and a waterproof chamber for electronics equipment, are required for the final system. In the future, we plan to employ green energy by using solar cells. A large-scale trial could also be conducted in different cities. In addition, for network connectivity, Wi-Fi and LoRa are utilized, but alternatives such as cellular connectivity or ZigBee could be utilized.

Author Contributions: Conceptualization, J.H.R., M.B.; methodology, J.H.R., M.B.; software, J.H.R. and N.K.; validation, M.B.; resources, N.K., M.A.R., M.B. and J.H.R.; data curation, N.K., M.A.R., M.B. and J.H.R.; writing-original draft preparation, J.H.R.; writing-review and editing, M.B., M.M.I.; visualization, N.K., J.H.R. and M.A.R.; supervision, M.B.; project administration, M.B.; Technical review and idea formulation, J.U. All authors have read and agreed to the published version of the manuscript.

Funding: This research is funded by Woosong University Academic Research in 2021.

Data Availability Statement: All the data presented in this study are available on request to the corresponding author.

Conflicts of Interest: The authors declare no conflict of interest.

\section{References}

1. Health Definition. Available online: https://www.who.int/about/who-we-are/frequently-asked-questions (accessed on 30 April 2021).

2. Jahan, M. Impact of Rural Urban Migration on Physical and Social Environment: The Case of Dhaka City. Int. J. Dev. Sustain. 2012, 1, 186-194.

3. List of Countries and Dependencies by Population Density. Available online: https://en.wikipedia.org/wiki/List_of_countries_ and_dependencies_by_population_density (accessed on 30 April 2021).

4. Dhaka Population 2021 (Demographics, Maps, Graphs). Available online: https:/ /worldpopulationreview.com/world-cities/ dhaka (accessed on 30 April 2021).

5. Dhaka. Available online: https://en.wikipedia.org/wiki/Dhaka (accessed on 30 April 2021).

6. Tiwari, R.R. Occupational health hazards in sewage and sanitary workers. Indian J. Occup. Environ. Med. 2008, 12, 112-115. [CrossRef] [PubMed]

7. Khan, E.T.A. Dhaka Water Supply and Sewerage Authority: Performance and Challenges. Available online: http://app.dwasa. org.bd/admin/news/Dhaka\%20WASA\%20Article-for\%20BOOK.pdf (accessed on 30 April 2021).

8. Reza, A.; Yousuf, T. Impacts of Waste Dumping on Water Quality in the Buriganga River, Bangladesh and Possible Mitigation Measures. J. Environ. 2016, 11, 35-40.

9. Annual Floor Report. Available online: http:/ /www.ffwc.gov.bd/images/annual19.pdf (accessed on 30 April 2021).

10. Nahrin, K. Urban development policies for the provision of utility infrastructure: A case study of Dhaka, Bangladesh. Util. Policy 2018, 54, 107-114. [CrossRef] 
11. Madakam, S.; Ramaswamy, R.; Tripathi, S. Internet of Things (IoT): A literature review. J. Comput. Commun. $2015,3,164-173$. [CrossRef]

12. IP Sensing-Telemetry Solutions for Water and Sewer Utilities-Automatic Water Meter Reading AMR, Vacuum Sewer System VSS_Pit-Bull Radio System. Available online: http://ipsensing.com/smms_management.htm (accessed on 30 April 2021).

13. Applications of the IP Camera in the Sewage Treatment Plant. Available online: https://en.cnki.com.cn/Article_en/CJFDTotalGZXG201103012.htm (accessed on 30 April 2021).

14. Talukder, S.; Sakib, I.I.; Talukder, Z.R.; Das, U.; Saha, A.; Bayev, N.S.N. USenSewer: Ultrasonic Sensor and GSM-Arduino based Automated Sewerage Management. In Proceedings of the 2017 International Conference on Current Trends in Computer, Electrical, Electronics and Communication (CTCEEC), Mysore, India, 8-9 September 2017; Institute of Electrical and Electronics Engineers (IEEE): Piscataway, NJ, USA, 2017; pp. 12-17.

15. Latif, S.L.; Afzaal, H.A.; Zafar, N.A. Modeling of Sewerage System Using Internet of Things for Smart City. In Proceedings of the 2017 International Conference on Frontiers of Information Technology (FIT), Islamabad, Pakistan, 18-20 December 2017; Institute of Electrical and Electronics Engineers (IEEE): Piscataway, NJ, USA, 2017; pp. 46-51.

16. Edmondson, V.; Cerny, M.; Lim, M.; Gledson, B.; Lockley, S.; Woodward, J. A smart sewer asset information model to enable an 'Internet of Things' for operational wastewater management. Autom. Constr. 2018, 91, 193-205. [CrossRef]

17. Liu, Y.; Zhang, W.; Cui, X.; Zhang, G.; Wang, G. City Pipe Network Intelligent Service Based on GIS and Internet of Things. In Proceedings of the 2014 7th International Conference on Intelligent Computation Technology and Automation, Changsha, China, 24-26 October 2014; Institute of Electrical and Electronics Engineers (IEEE): Piscataway, NJ, USA, 2014; pp. $936-939$.

18. Brandstetter, A.; Engel, R.L.; Cearlock, D.B. A Mathematical Model for Optimum Design and Control of Metropolitan Wastewater Management Systems. J. Am. Water Resour. Assoc. 1973, 9, 1188-1200. [CrossRef]

19. Cao, L. Wireless mesh monitoring system for sewage treatment plant. In Proceedings of the 2009 ISECS International Colloquium on Computing, Communication, Control, and Management, Sanya, China, 8-9 August 2009; Volume 4, pp. 350-353. [CrossRef]

20. Pasha, S. Thingspeak Based Sensing and Monitoring System for IoT with Matlab Analysis. Int. J. New Technol. Res. $2016,2,5$.

21. Nasution, T.H.; Muchtar, M.A.; Siregar, I.; Andayani, U.; Christian, E.; Sinulingga, E.P. Electrical appliances control prototype by using GSM module and Arduino. In Proceedings of the 2017 4th International Conference on Industrial Engineering and Applications (ICIEA), Nagoya, Japan, 21-23 April 2017; Institute of Electrical and Electronics Engineers (IEEE): Piscataway, NJ, USA, 2017; pp. 355-358.

22. Li, L.; Xiaoguang, H.; Ke, C.; Ketai, H. The Applications of WiFi-Based Wireless Sensor Network in Internet of Things and Smart Grid. In Proceedings of the 2011 6th IEEE Conference on Industrial Electronics and Applications, Beijing, China, 21-23 June 2011; pp. 789-793.

23. Novo, O.; Beijar, N.; Ocak, M.; Kjallman, J.; Komu, M.; Kauppinen, T. Capillary networks—bridging the cellular and IoT worlds. In Proceedings of the 2015 IEEE 2nd World Forum on Internet of Things (WF-IoT), Milan, Italy, 14-16 December 2015; Institute of Electrical and Electronics Engineers (IEEE): Piscataway, NJ, USA, 2015; pp. 571-578.

24. Guo, W.; Healy, W.M.; Zhou, M. ZigBee-Wireless Mesh Networks for Building Automation and Control. In Proceedings of the 2010 International Conference on Networking, Sensing and Control (ICNSC), Chicago, IL, USA, 10-12 April 2010 ; pp. 731-736.

25. Lavric, A.; Popa, V. Internet of Things and LoRaTM Low-Power Wide-Area Networks: A Survey. In Proceedings of the 2017 International Symposium on Signals, Circuits and Systems (ISSCS), Iasi, Romania, 13-14 July 2017; pp. 1-5.

26. Sengupta, N.; Chinnasamy, R. Designing of an Immaculate Smart City with Cloud Based Predictive Analytics. In Proceedings of the 2nd Smart Cities Symposium (SCS 2019), Zallaq, Bahrain, 24-26 March 2019; pp. 1-7.

27. Islam, M.; Uddin, J.; Kashem, M.A.; Rabbi, F.; Hasnat, W. Design and Implementation of an IoT System for Predicting Aqua Fisheries Using Arduino and KNN. In Proceedings of the Intelligent Human Computer Interaction, Daegu, Korea, 24-26 November 2020; Singhm, M., Kang, D.-K., Lee, J.-H., Tiwary, U.S., Singh, D., Chung, W.Y., Eds.; Springer International Publishing: Cham, Switzerland, 2021; pp. 108-118.

28. ESP32 Wi-Fi \& Bluetooth MCU I Espressif Systems. Available online: https://www.espressif.com/en/products/socs/esp32 (accessed on 30 April 2021).

29. GSM. Available online: https:/ / en.wikipedia.org/w/index.php?title=GSM\&oldid=1020444251 (accessed on 30 April 2021).

30. IoT Based Home Automation System Using ThingSpeak. Available online: https://ieeexplore.ieee.org/document/8941737/ (accessed on 30 April 2021).

31. Khan, E.T.A. Annual Report-Dwasa. Available online: https://bit.ly/2SdC8xM (accessed on 30 April 2021). 